Vision

\section{Trichromatic vision in prosimians}

Trichromatic vision in primates is achieved by three genes encoding variants of the photopigment opsin that respond individually to short, medium or long wavelengths of light. It is believed to have originated in simians because so far prosimians (a more primitive group that includes lemurs and lorises) have been found to have only monochromatic or dichromatic vision $^{1-3}$. But our analysis of the X-chromosome-linked opsin gene in 20 representative prosimian species provides evidence for trichromacy in ancestral and extant prosimians, indicating that it may have originated much earlier than is commonly believed.

Trichromacy in humans, apes, Old World monkeys and howler monkeys ${ }^{4}$ (a genus of New World monkey) is due to a short-wavelength-sensitive $(S)$ opsin gene on an autosome and a middle- $(M)$ and a long-wavelength $(L)$ opsin gene on the X chromosome ${ }^{1}$. Other New World monkeys have only one autosomal and one X-linked opsin gene, but a polymorphism at the Xlinked locus enables heterozygous female New World monkeys to be trichromatic ${ }^{1,5}$, although males and homozygous females are dichromatic.

In contrast, nocturnal prosimians are thought to be monochromatic, as they have no functional autosomal opsin gene ${ }^{3}$.
Diurnal prosimians have a functional autosomal opsin gene and a functional X-linked opsin gene, but so far no polymorphism at either locus has been found ${ }^{2}$. The spectral wavelength-sensitivity maxima $\left(\lambda_{\max }\right)$ of opsins from four lemurs from each of two species have been measured by using electroretinographic flicker photometry ${ }^{2}$ : only a single class of $\mathrm{X}$-linked opsin was detected, with $\lambda_{\max }$ at about $543 \mathrm{~nm}$, indicating that prosimians have no polymorphism at the X-linked opsin locus and are at best dichromatic ${ }^{2}$. But because this conclusion was based on a small sample size, we studied 20 species representing the major prosimian lineages and did population screenings on several species by sequencing exons 3, 4 and 5 of the X-linked opsin gene.

These screenings revealed that there is an $M / L$ polymorphism in both Coquerel's sifaka (Propithecus verreauxi coquereli) and the red ruffed lemur (Varecia variegata rubra) (Table 1), which represent the two major diurnal prosimian lineages. The $M$ opsin is presumably of the same type as that found in diurnal lemurs and bushbabies $^{2,3,6}$, but the $L$ opsin has not been detected before. The two alleles are quite common in both species, with the $M$ allele having a frequency of $42 \%$ in the red ruffed lemur, for example, although this estimate has a large standard error. The $M / L$ polymorphism is also found in a nocturnal prosimian, the greater dwarf lemur (Cheirogaleus major).

\begin{tabular}{|c|c|c|c|c|c|c|}
\hline \multirow[t]{2}{*}{ Family } & \multirow[t]{2}{*}{ Species } & \multicolumn{2}{|c|}{ Samples } & \multirow[t]{2}{*}{ X chromosomes } & \multicolumn{2}{|c|}{ Alleles } \\
\hline & & Male & Female & & M & $L$ \\
\hline \multirow[t]{3}{*}{ Loridae (N) } & Slender loris & 0 & 1 & 2 & 2 & 0 \\
\hline & Common slow loris & 0 & 1 & 2 & 2 & 0 \\
\hline & Potto & 1 & 0 & 1 & 1 & 0 \\
\hline \multirow[t]{2}{*}{ Galagonidae (N) } & Greater bushbaby & 0 & 1 & 2 & 2 & 0 \\
\hline & Lesser bushbaby & 1 & 1 & 3 & 3 & 0 \\
\hline Daubentoniidae (N) & Aye-aye & 0 & 3 & 6 & 6 & 0 \\
\hline \multirow[t]{2}{*}{ Indridae (D) } & Coquerel's sifaka & 9 & 10 & 29 & 4 & 25 \\
\hline & Golden-crowned sifaka & 0 & 1 & 2 & 2 & 0 \\
\hline \multirow[t]{4}{*}{$\begin{array}{l}\text { Cheirogaleidae }(\mathrm{N}) \\
\ldots\end{array}$} & Greater dwarf lemur & 3 & 1 & 5 & 4 & 1 \\
\hline & Coquerel's dwarf lemur & 1 & 1 & 3 & 0 & 3 \\
\hline & Fat-tailed dwarf lemur & 9 & 3 & 15 & 15 & 0 \\
\hline & Grey mouse lemur & 0 & 2 & 4 & 0 & 4 \\
\hline \multirow[t]{6}{*}{$\begin{array}{l}\text { Lemuridae (D) } \\
\text {...................... }\end{array}$} & Red ruffed lemur & 2 & 5 & 12 & 5 & 7 \\
\hline & Black/white ruffed lemur & 4 & 1 & 6 & 6 & 0 \\
\hline & Brown lemur & 1 & 0 & 1 & 1 & 0 \\
\hline & Mongoose lemur & 0 & 2 & 4 & 4 & 0 \\
\hline & $\begin{array}{l}\text { Ring-tailed lemur } \\
.\end{array}$ & $\begin{array}{c}1 \\
\ldots .\end{array}$ & 0 & 1 & 1 & 0 \\
\hline & Bamboo lemur & 1 & 0 & 1 & 0 & 1 \\
\hline \multirow[t]{2}{*}{$\begin{array}{l}\text { Tarsiidae (N) } \\
\text {.................... }\end{array}$} & Philippine tarsier & 5 & 10 & 25 & 0 & 25 \\
\hline & Western tarsier & 5 & 1 & 7 & 7 & 0 \\
\hline
\end{tabular}

The identification of $M$ and $L$ opsins was based on amino acids at the residue sites responsible for spectral tuning. Previous studies ${ }^{9-12}$ have identified five critical sites in exons 3,4 and 5 (amino-acid positions $180,229,233,277$ and 285) causing a spectral shift of $\sim 5,2,1,8$ and $15 \mathrm{~nm}$, respectively. The $M$ opsin found in tarsiers and most Madagascan lemurs has the amino acids alanine, isoleucine, serine, tyrosine and alanine at these sites, which are identical to those of the marmoset and tamarin P543 allele ${ }^{12,13}$. The $M$ opsin found in bushbabies, lorises, pottos and aye-ayes differs from the P543 allele only at position 229, having valine instead of isoleucine, consistent with a study of two bushbabies ${ }^{6}$. This difference is unlikely to affect spectral tuning ${ }^{9-12}$ as it does not involve a hydroxyl group, so $\lambda_{\max }$ is estimated for both $M$ opsins to be $543 \mathrm{~nm}$, the same as that of the marmoset $P 543$ allele. The $L$ opsin has alanine, isoleucine, serine, tyrosine and threonine at the five critical sites, which are identical to those of the P558 allele in the saki monkey, a New World monkey (Y. Tan and W.-H. Li, unpublished data), so its $\lambda_{\max }$ is estimated at about $558 \mathrm{~nm}$. The three species polymorphic for the $M$ and $L$ alleles are shown in bold. N, nocturnal; D, diurnal.
The X-linked opsin polymorphism and the autosomal opsin gene should enable a heterozygous female lemur to produce three classes of opsin cone, making it trichromatic in the same way as many New World monkeys. Behavioural and spectral studies of heterozygous female lemurs have yet to demonstrate trichromacy, but the possibility is supported by anatomical and physiological findings showing many similarities in the organization of prosimian and simian visual systems ${ }^{7}$, such as the parvocellular (P-cell) system, which is specialized for trichromacy by mediating redgreen colour opponency ${ }^{8}$.

The phylogenetic distribution of the $M$ and $L$ opsins supports the idea that the Xlinked opsin polymorphism and primate trichromacy arose early during primate evolution. Under the parsimony criterion, our observation that $M$ and $L$ opsin genes intermingle between species within each of the three major families of Madagascan lemurs (Indridae, Cheirogaleidae and Lemuridae) (Table 1), together with the finding of the polymorphism in some species, indicates that the ancestral strepsirhine may have been polymorphic at the X-linked opsin locus and therefore trichromatic.

We found that the western tarsier (Tarsius bancanus) has an $M$ opsin and that the Philippine tarsier ( $T$. syrichta) has an $L$ opsin, indicating that their diurnal common ancestor had an $M / L$ polymorphism and was trichromatic. The common ancestor of tarsiers and strepsirhines might therefore also have been trichromatic. Although the $\mathrm{X}$-linked opsin polymorphism in prosimians may have arisen independently of that in New World monkeys, the P543 and P558 alleles of New World monkeys might have descended from the tarsiers.

Ying Tan, Wen-Hsiung Li

Department of Ecology and Evolution, University of Chicago, 1101 East 57th Street,

Chicago, Illinois 60637, USA

e-mail:whli@uchicago.edu

1. Jacobs, G. H. Biol. Rev. 68, 413-471 (1993).

2. Jacobs, G. H. \& Deegan, J. F. II Am. J. Primatol. 30, 243-256 (1993).

3. Deegan, J. F. II \& Jacobs, G. H. Am. J. Primatol. 40, 55-66 (1996).

4. Jacobs, G. H., Neitz, M., Deegan, J. F. II \& Neitz, J. Nature 382, 156-158 (1996).

5. Travis, D. S., Bowmaker, J. K. \& Mollon, J. D. Vision Res. 28, 481-490 (1988).

6. Zhou, Y.-H., Hewett-Emmett, D., Ward, J. P. \& Li, W.-H. J. Mol. Evol. 45, 610-618 (1997).

7. Casagrande, V. A. \& Kaas, J. H. in Cerebral Cortex, Vol. 10, Primary Visual Cortex in Primates (eds Peters, A. \& Rockland, K. S.) 201-259 (Plenum, New York, 1994).

8. Yamada, E. S., Marshak, D. W., Silverira, L. C. L. \& Casagrande, V. A. Vision Res. 38, 3345-3352 (1998).

9. Neitz, M., Neitz, J. \& Jacobs, G. H. Science 252, 971-974 (1991) 10. Merbs, S. L. \& Nathans, J. Photochem. Photobiol. 58, 706-710 (1993).

11. Asenjo, A. B., Rim, J. \& Oprian, D. D. Neuron 12, 1131-1138 (1994).

12. Shyue, S.-K. et al. J. Mol. Evol. 46, 697-702 (1998).

13. Hunt, D. M., Williams, A. J., Bowmaker, J. K. \& Mollon, J. D. Vision Res. 33, 147-154 (1993). 